\title{
Expression of Class 5 Antigens by Meningococcal Strains Obtained From Patients in Brazil and Evaluation of Two New Monoclonal Antibodies
}

\author{
Elizabeth N. De Gaspari and Wendell D. Zollinger
}

\author{
Adolfo Lutz Institute, São Paulo, SP, Brazil
}

Walter Reed Army Institute, Maryland, USA

\begin{abstract}
Determining the profile of antigen expression among meningococci is important for epidemiologic surveillance and vaccine development. To this end, two new mouse monoclonal antibodies (MAbs) have been derived against Neisseria meningitidis proteins (class 5). The MAbs were reactive against outer membrane antigens and were bactericidal. Selected anti-class 5 MAbs [(5.1)-3E6-2; (5.3)-3BH4-C7; (5.4)-1BG11-C7; (5.5)-3DH-F5G9 also 5F1F4-T3(5.c)], and the two new monoclonal antibodies $\mathrm{C} 14 \mathrm{~F} 10 \mathrm{Br} 2(5.8)$ and $7 \mathrm{~F} 11 \mathrm{BSBr} 3(5.9)$, were then tested against different meningococcal strains, (63 strains of serogroup $A, 60$ strains of serogroup $C$ (from 1972 to 1974); and 136 strains of serogroup B (from 1992) meningococci). Our results demonstrated that the expression of class 5 proteins in the $N$. meningitidis B Brazilian strains studied is highly heterogeneous. The serotypes and subtypes of $B: 4: P 1.15, B: 4: P 1.9, B: 4: P 1.7$, B:4:P1.3, B:4:P1.14, B:4:P1.16, B:4:NT, and B:NT:NT were detected in N. meningitidis B serogroups.The strains $C: 2 \mathrm{a}: P 1.2$ and $A: 4.21: P 1.9$ were dominant in the $C$ and $A$ serogroups, respectively. Serogroup B organisms expressed the class 5 epitopes $5.4(18 \%), 5.5(22 \%), 5.8$ (3.6\%), $5.9(8.0 \%)$ and $5 \mathrm{c}(38 \%)$. Serogroup $C$ expressed class 5 epitopes $5.1(81 \%), 5.4$ $(35 \%), 5.5(33 \%)$ and $5.9(5.0 \%)$; and serogroup A showed reactivity directed at the class 5 protein $5 \mathrm{c}(47 \%)$; and reactivity was present with the new monoclonal antibody, $5.9(5.5 \%)$. We conclude that the two new MAbs are useful in detecting important group B, class 5 antigens, and that a broad selection of serogroup $B$, class 5 proteins would be required for an effective vaccine based on the class 5 proteins.
\end{abstract}

Key Words: Neisseria meningitidis, monoclonal antibodies, outer membrane protein, Flow cytometry.

Meningococci have been classified into serogroups [1], based on their capsular polysaccharides. These serogroups differ in the characteristics of the diseases they cause. Meningococci of serogroup A are responsible for epidemics, particularly in sub-Saharan Africa [2] and China [3], whereas endemic disease and limited outbreaks in developed countries are mainly associated with serogroups B and C [4].

Received on 14 April 2001; revised 21 June 2001.

Address for correspondence: Dr. Elizabeth N. De Gaspari. Instituto Adolfo Lutz, Seção de Imunologia - Av. Dr Arnaldo 355, 11 andar,Zip code: 01246-902, São Paulo, SP- Brazil. Phone: (55) (011)-3068-28-98. Fax: (55) (011)-3085-35-05.

E-mail: egaspari@ial.sp.gov.br

The Brazilian Journal of Infectious Diseases 2001;5(3):143-153 (C) 2001 by The Brazilian Journal of Infectious Diseases and Contexto Publishing. All rights reserved.

1413-8670
The incidence of meningococcal disease (MD) in Brazil has been monitored since the serogroup A and C epidemics that occurred between 1971 and 1974. In 1974, the number of cases exceeded 179 cases per 100,000 inhabitants [5,6]. The incidence of MD due to $N$. meningitidis serogroup $\mathrm{C}$ in the greater $\mathrm{São}$ Paulo area of Brazil, has been low since the end of the epidemics of 1971 and 1972. Between 1972 and 1974, there was an overlapping of two epidemic waves; one caused by serogroup C (91\% of all MD cases in 1972), and another, larger wave caused by serogroup A ( $90 \%$ of all MD cases in 1974). Between 1981 and 1987 , about $83 \%$ of the meningococcal isolates were identified as serogroup B, whereas only $6 \%$ corresponded to serogroup C strains. In 1988, the incidence of MD in the greater São Paulo area, state of São Paulo, was over 4 per 100,000 inhabitants. 
It was caused by serogroup B strains in 1988 and 1989, and by serogroups B and C strains in 1990 [7]. During this period, the $N$. meningitidis serogroup B isolates obtained from MD cases were characterized by serological typing as B:4:P1.15, and by multilocus enzyme electrophoresis as belonging to 1 distinct cluster, included in the ET-5 complex of a group of 22 closely related ETs [8].

The major proteins of the outer membrane of $N$. meningitidis are designated class 1 through class 5 [10]. Class 1, 2, and 3 proteins are porins, and they show a limited antigenic variation that has been used to define serotypes and subtypes [11,12].

Class 5, or opacity (Opa), proteins are a family of antigenically variable outer membrane proteins of $N$. meningitidis [4]. These class 5 proteins are heatmodifiable and vary in size from $25 \mathrm{kD}$ to $30 \mathrm{kD}$. Meningococci contain 4 opa genes that contain multiple repeats of the sequence CTCTT which results in phase variation of gene product expression due to slip-strand misparing which leads to a shift in the reading frame. As a result, the number of Opa proteins expressed varies from strain to strain [13-15]. The class 5 proteins encoded by opa genes (Opa proteins) have fairly constant sequences, except for 2 hypervariable (HV) regions [16-19]. Meningococci isolated on different continents, and defined by multilocus enzyme electrophoresis as belonging to the ET-37 complex, contain both shared and unique Opa $\mathrm{HV}$ regions encoding epitopes recognized by monoclonal antibodies (MAbs), and show evidence of recombinational reassortment of the $\mathrm{HV}$ regions $[8,9]$. The class 5 protein called Opc or $5 \mathrm{c}$ is encoded by the $o p c$ gene and differs from Opa proteins $[20,21]$ with which it shows only $22 \%$ amino acid sequence homology [22].

Bacteria isolated from the nasopharynx of patients and healthy carriers were found to express large amounts of 5c, whereas those isolated from cerebrospinal fluid or blood preferentially expressed small amounts of the protein [16]. This suggested that $5 \mathrm{c}$ might be important for adhesion to epithelial cells and that down-regulated variants might be selected during invasion.
The class 5 proteins have a basic isoelectric point, a trimeric structure, hypervariability of expression, heat modifiability and surface exposure. It should be pointed out that meningococcal class 5 proteins seem to induce strong strain-specific IgG antibody responses in humans after meningococcal disease and are also highly immunogenic in mice, where they elicit strain-specific bactericidal antibodies [22].

Until now, the frequency of most class 5 proteins expressed by Brazilian meningococcal strains had not been determined serologically. Here we present the results of such tests. This analysis is relevant for the development of a vaccine against this microorganism since it aids in allowing a careful selection of antigens for vaccine formulation. The preparation of 2 novel monoclonal antibodies specific for epitopes present in the class 5 protein derived from a Brazilian $N$. meningitidis epidemic strain, contribute to the determination of class 5 proteins to be included as antigens in the future vaccine for meningitis of serogroup $\mathrm{B}$ in Brazil. These MAbs are available for future use in class 5 evaluations in other countries.

\section{Materials and Methods}

\section{Origin of the strains}

All meningococci of serogroups A, B, or C, were isolated from the blood or cerebrospinal fluid specimens of patients with systemic disease and have been deposited in the strain collection of the Adolfo Lutz Institute. Following biochemical identification [23], the strains were serogrouped by the slide agglutination technique using antisera against the 9 major capsular serogroups of $N$. meningitidis in the Bacteriology Section of the Adolfo Lutz Institute. These antisera were prepared by the National Reference Center for Meningitis in the Immunology Section of the Adolfo Lutz Institute [24]. We analyzed $63 N$. meningitidis strains of serogroup A, 60 strains of serogroup C (from the 1972-1974 epidemics) from the culture collection at the Adolfo Lutz Institute, and 136 strains of serogroup B (from 1992) obtained from the Bacteriology Section of the Adolfo Lutz Institute. 
The bacteria were grown overnight in a candle jar on Tryptic Soy Broth (TSB; Difco BRL products, Gaithersburg, MD) supplemented with $1 \%$ horse serum (Sigma, St.Louis, MO) in plates in a $5 \% \mathrm{CO}_{2}$ atmosphere at $37^{\circ} \mathrm{C}$. We confirmed the serogroups used in the present investigation using MAbs for capsular serogroups A (2D7-B-5), B (5C1-3H7), C (7H9-4), W (6G9-7) and Y (2C2-4.6).

\section{Production of mouse monoclonal antibody}

The 2 new monoclonal antibodies were obtained by fusion of mouse spleen cells with the murine myeloma line X63-Ag8.653 [25] as described [26]. Mice were immunized with 4 doses of meningococci $\mathrm{B}: 4: \mathrm{P} 1.9$ strain inactivated at $56^{\circ} \mathrm{C}$, both intraperitoneally and intravenously, 3 days before fusion. Hybridomas were expanded and cultured in the peritoneal cavities of Pristane-primed mice to obtain ascitic fluid. All procedures with animals were in accordance with the principles of the Brazilian Code for the Use of Laboratory Animals. The anti-class 5 MAbs selected for this study were: 3E6-2 (5.1), 3BH4-C7 (5.3), 1BG11-C7 (5.4), 3DH-F5G9 (5.5), and 5F1F4-T3(5c), and the 2 new monoclonal antibodies C14F10Br2 (5.8) and 7F11B5Br3 (5.9). Except for the 2 novel ones (5.8) and (5.9), the remaining anti-class 5 monoclonal antibodies were prepared in the laboratory of one of the authors (WZ). The specificities of the 5.8 and 5.9 MAbs were determined by dot ELISA. The class and subclass of the 2 new MAb were determined by ELISA using conjugated anti-mouse immunoglobulins as described by the manufacturer (mouse hybridoma subtyping kits, Boehringer, Mannheim).

Preparation of outer membrane complex $(O M C)$ and outer membrane protein (OMP) of N.meningitidis

OMC and OMP were prepared from the B:4:P1.9 Brazilian epidemic strain of $N$. meningitidis. Outer membrane components (OMC) were extracted in 5 $\mathrm{mL}$ of buffer solution $(0.1 \mathrm{M}$ sodium acetate and 0.2 $\mathrm{M}$ lithium cloride, $\mathrm{pH}$ 5.8) per g (wet weight) of cells by shaking with $2 \mathrm{~mm}$ diameter glass beads in a gyrating water bath at $45^{\circ} \mathrm{C}$ for $2 \mathrm{~h}$. Purified OMC were obtained by removing cells by centrifugation at 12,000 $\mathrm{g}$ for $20 \mathrm{~min}$ and the supernatant was dialyzed overnight in $0.15 \mathrm{M} \mathrm{NaCl}$. OMP was prepared as described by Zollinger, et al. [27] Protein concentration was determined by the method of Lowry, et al. [28].

Antibody screening by enzyme immunoassay (ELISA)

ELISA was performed as described by Harthug, et al. [29], with OMC or OMP at a protein concentration of $5 \mathrm{mg} / \mathrm{mL}$ as the coating antigen and a peroxidase-conjugated goat anti-mouse IgG (Sigma ,St.Louis,MO) as a detection system. For isotype determination, $100 \mu \mathrm{l}(5 \mu \mathrm{g} / \mathrm{mL}$ concentration $)$, of OMP or OMC of the homologous strain B:4:P1.9 in phosphate buffered saline were dispensed into the wells of flat-bottom microtiter plates (Costar, Cambridge, MA) and allowed to adsorb for $18 \mathrm{~h}$ at room temperature.

\section{Dot-Blot}

Dot-blot analyses were performed as described by Rosenquist, et al. [30]. Strain suspensions were made in phosphate buffered saline (PBS), $\mathrm{pH} 7.4$, containing $0.02 \%$ sodium azide. The cells were heat inactivated at $56^{\circ} \mathrm{C}$ for $30 \mathrm{~min}$, and the absorbance of the suspensions was adjusted to 1.0 at $650 \mathrm{~nm}$ using a spectrophotometer (model Spectronic 88). The bacterial cell suspension was stored at $4^{\circ} \mathrm{C}$. For Dotblot, $1 \mu$ l of meningococcal cell suspension was dotted onto $0.22 \mathrm{~mm}$ pore size Schleicher \& Schuell (S.S) nitrocellulose strips. After drying, the strips were incubated for $1 \mathrm{~h}$ in a blotting buffer containing $2.5 \%$ bovine serum albumin (BSA) in PBS. The MAbs were pipetted directly into the blocking buffer according to the test for the standardization of the dilution of the MAbs used in the present study. The incubation in the presence of MAbs was carried out overnight at room temperature at 1:50,000 dilution. Next, the strips were separately washed 6 times with PBS. Antibody binding 
Figure. 1. Immunoblots of (B:4:P1.9) OMC case strain of Neisseria meningitidis $\mathrm{B}$ reacted with monoclonal antibodies . a) class 1 ( $46 \mathrm{kD})$; b) class $3(34 \mathrm{kD})$; c) class $4(32 \mathrm{kD})$; d) class $5(28 \mathrm{kD}) \mathrm{C} 14 . \mathrm{F} 10 \mathrm{Br} 2(1: 20,000)$; and e) class $5(28 \mathrm{kD}) 7 \mathrm{~F} 1.1 \mathrm{~B} 5 \mathrm{Br} 3(1: 5,000)$; f) Molecular weight standards are indicated in kilodaltons. Solubilization for electrophoresis was done at $100^{\circ} \mathrm{C}$

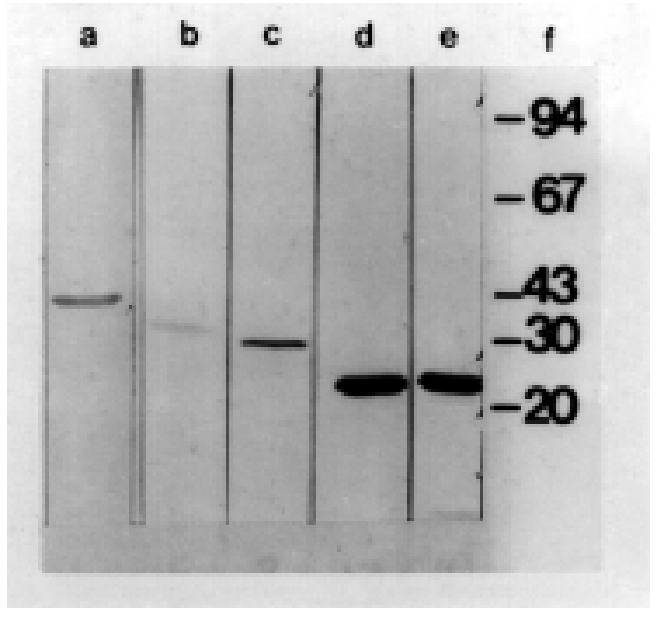

Figure 2. Dot plots of indirect immunofluorescence activated cell sorter analyses with whole cells (wc) of $N$. meningitidis B4:P1.9 ( homologous strain ). a) saline; b) unrelated IgG MAb; c) MAb 5F81 A4 (class 1); d) MAb 5DC4-C8-C3 (class 4); e) MAb C14 F10 Br2 class (5.8); f) MAb 7F1 IB5 Br3 class (5.9). The monoclonals used in FACS analyses and the IgG-FITC labeled second antibody were used at 1:1000 dilution

a)

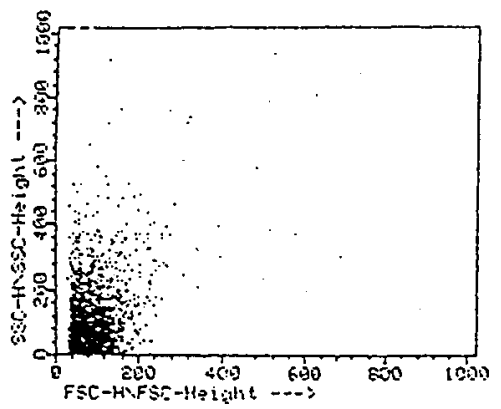

d)

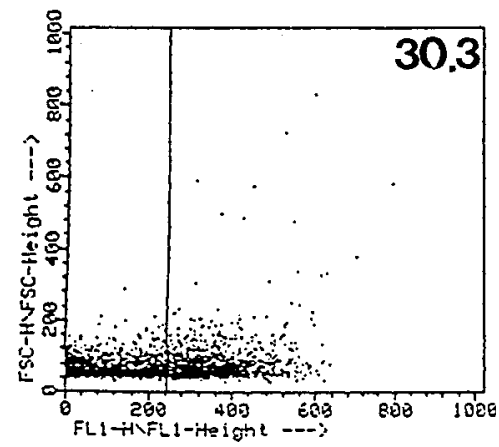

b)

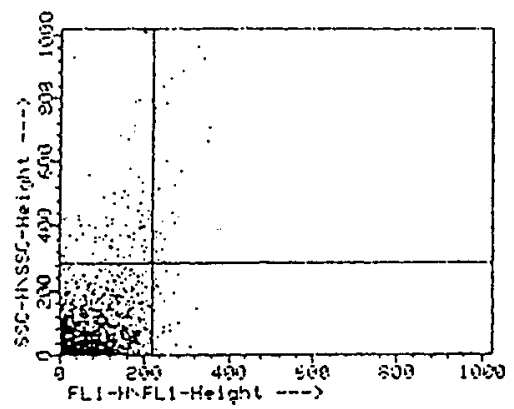

e)

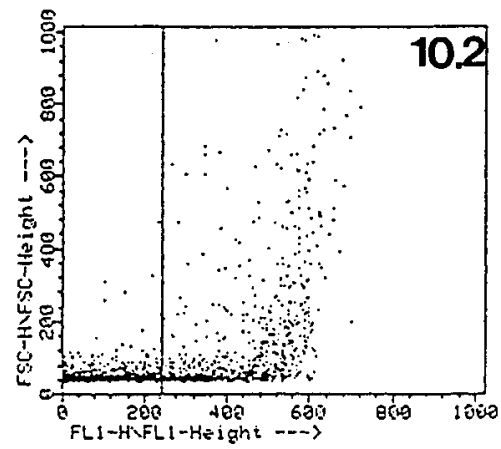

c)

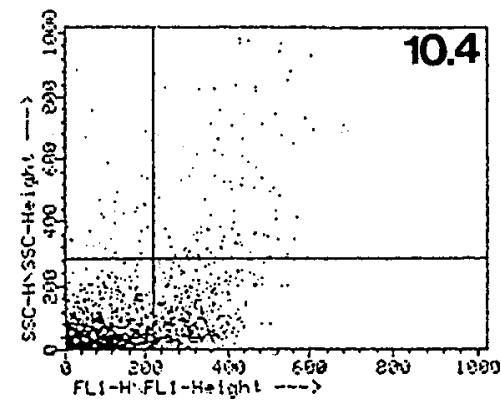

f)

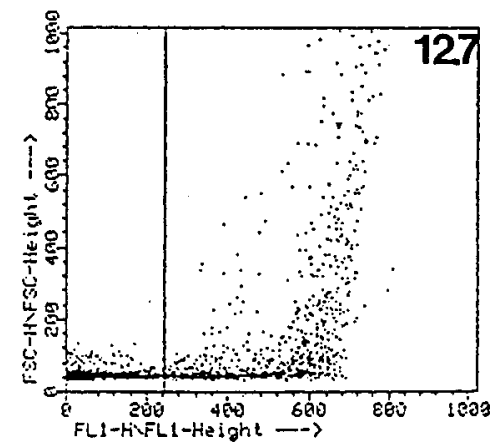


Table 1. Bactericidal titers of ascites fluids containing - C14F10 (5.8) and 7F11B5 (5.9) monoclonal antibodies against $N$. meningitidis $\mathrm{B}: 4: \mathrm{P} 1.9$ (homologous strain)

\begin{tabular}{lcc}
\hline Dilution & MAb (5.8) & MAb (5.9) \\
$1: 5000$ & $88 \%$ & $96 \%$ \\
$1: 10000$ & $56 \%$ & $48 \%$ \\
\hline
\end{tabular}

The reciprocal of the antibody dilution yielding $50 \%$ killing of meningococci was considered to be the bactericidal titer.

Table 2. ELISA reactivity using ascites and outer membrane complex (OMC) and outer membrane protein (OMP) antigens of N.meningitidis strain B:4:P1.9 (homologous strain)

\begin{tabular}{lcc}
\hline Antigens & \multicolumn{2}{c}{ ELISA } \\
\hline & $\mathrm{MAb}(5.8)$ & $\mathrm{MAb}(5.9)$ \\
OMC & $1: 128,000$ & $1: 64,000$ \\
OMP & $1: 256,000$ & $1: 128,000$ \\
\hline
\end{tabular}

Table 3. Frequency of class 5 expression in serogroups A, B, and C meningococci in Brazil during epidemics

\begin{tabular}{lccccccc}
\hline Strains tested & \multicolumn{7}{c}{ Specificity of monoclonal antibodies used** } \\
\hline & 5.8 & 5.9 & 5.1 & 5.3 & 5.4 & 5.5 & $5 \mathrm{c}$ \\
Serogroup A (n=63)) & $\mathrm{NR}$ & $5.5 \%$ & $\mathrm{NR}$ & $\mathrm{NR}$ & $\mathrm{NR}$ & $\mathrm{NR}$ & $47 \%$ \\
Serogroup B (n=136) & $3.6 \%$ & $8.0 \%$ & $\mathrm{NR}$ & $\mathrm{NR}$ & $18 \%$ & $22 \%$ & $38 \%$ \\
Serogroup C (n=60) & $\mathrm{NR}$ & $5.0 \%$ & $81 \%$ & $\mathrm{NR}$ & $35 \%$ & $33 \%$ & $\mathrm{NR}$ \\
\hline$*$ C14F10Br2(5.8), 7F11B5Br3(5.9), D12(5.1),3B4.C7(5.3), 1B61C7(5.4),3DH9F5G8(5.5) and 5F1F4.T3 (5c). \\
NR: no reactivity.
\end{tabular}




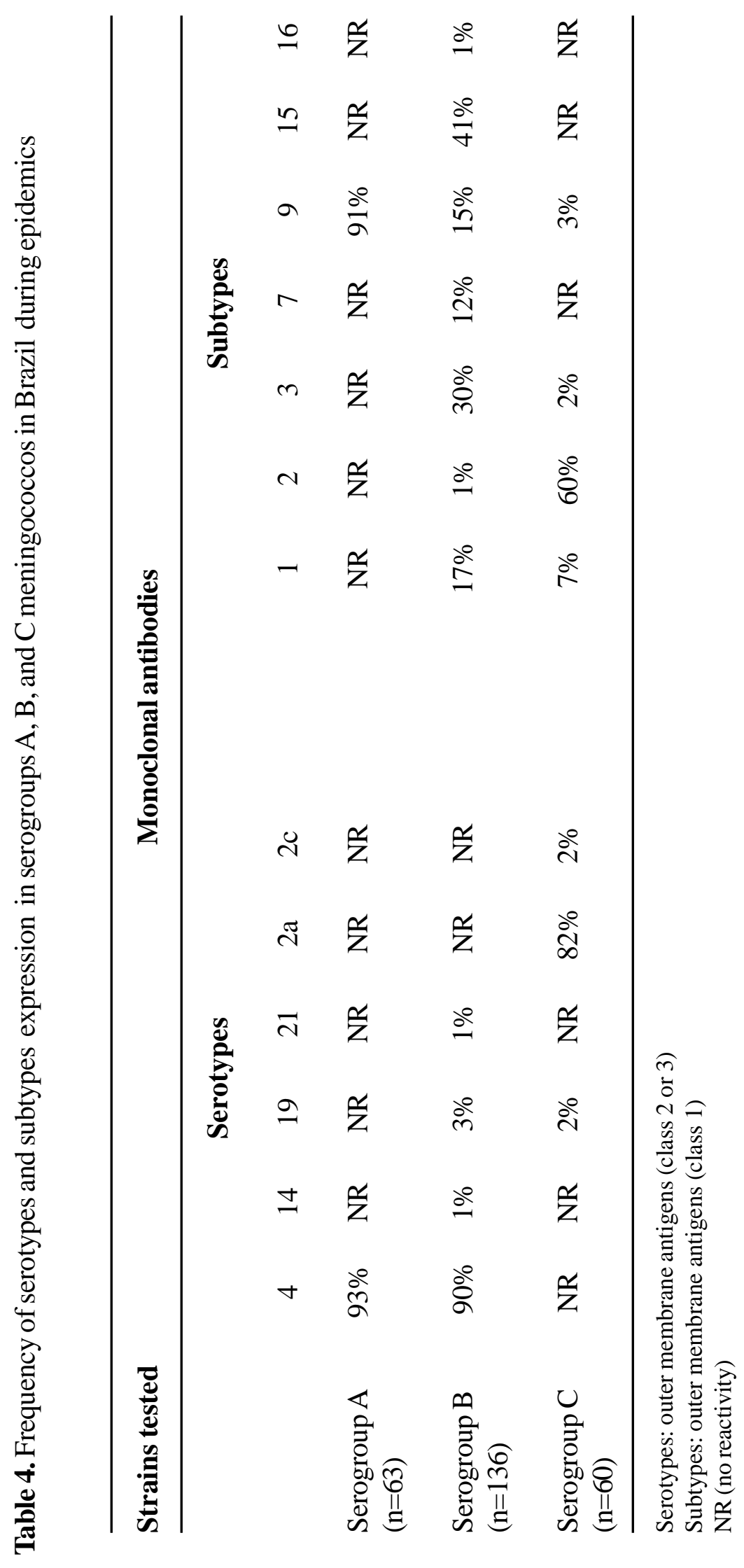

www.infecto.org.br/bjid.htm 
was detected after $2 \mathrm{~h}$ of incubation with a 1:1000 dilution peroxidase-conjugated of rabbit anti-mouse immunoglobulin (Dakopatts a/s, Denmark). The reaction was visualized by adding a freshly prepared solution containing $30 \% \mathrm{H}_{2} \mathrm{O}_{2}$ and $18 \mathrm{mg} / \mathrm{mL}$ of 4chloronaphthol in PBS.

This assay was used to determine the serotypes, as well as the class 5 epitopes, of Brazilian Neisseria meningitidis strains.

\section{SDS-PAGE and immunoblot analysis}

Whole cells of strain B:4:P1.9 were separated on sodium dodecyl sulfate (SDS) polyacrylamide gels by the method of Laemmli [31]. The stacking gel contained $4 \%$ acrylamide, and the resolving gel contained $12 \%$ acrylamide. The samples were prepared by mixing 1 part of whole cells with 1.0 absorbance at $650 \mathrm{~nm}$, with 1 part of sample buffer $(62.5 \mathrm{mM}$ Trishydrochloride, $\mathrm{pH} 6.8,1 \%$ (v/v) glycerol, $2 \%$ (wt/ v), $0.5 \% \operatorname{SDS}(\mathrm{v} / \mathrm{v}), 2 \%$ mercaptoethanol, $0.5 \%(\mathrm{w} /$ v) bromophenol blue and heated for $5 \mathrm{~min}$ at $100^{\circ} \mathrm{C}$ or for $1 \mathrm{~h}$ at $37^{\circ} \mathrm{C}$. Samples $(25 \mu \mathrm{l})$ were applied to each gel line. Electrophoresis was carried out at $50 \mathrm{~V}$ constant voltage until the bromophenol blue tracking dye entered the separating gel. A standard protein mixture (Pharmacia-LKB) was used for the determination of apparent molecular weight. After SDS-PAGE, proteins were transferred electrophoretically from the gel to nitrocellulose paper (S.S) by the methods of Towbin [32]. A constant potential of $5 \mathrm{~V} / \mathrm{cm}$ was applied to the gelnitrocellulose paper sandwich for $2 \mathrm{~h}$ in a semi-dry electroblotter, as specified by the manufacturer. The electroblotting buffer contained $25 \mathrm{mM}$ Trishydrochloride, $192 \mathrm{mM}$ glycine, and $20 \%$ (v/v) methanol, $\mathrm{pH}$ 8.3. Transferred proteins on the blot were stained with amido-black or detected by an enzyme immunoassay. To probe for bacterial antigens, the paper was soaked in 5\% PBS-BSA solution for $2 \mathrm{~h}$ to block nonspecific protein binding sites, and then incubated overnight with monoclonal antibodies diluted in $1.25 \%$ PBS-BSA. The sheet was washed 4 times with PBS and incubated with peroxidase-conjugated goat anti-mouse immunoglobulin (Sigma), also diluted in $1.25 \%$ PBSBSA. After $2 \mathrm{~h}$ incubation and 3 washes, the blots were soaked in a $30 \% \mathrm{H}_{2} \mathrm{O}_{2}$ and $18 \mathrm{mg} 4$ chloronaphthol in PBS.

\section{Bactericidal assay}

The microbactericidal assay was done as described by Hoiby [33], with minor modifications. Two-fold dilutions of the ascitic fluid of MAb C14F10.Br2 (5.8) and 7F11B5Br3 (5.9) were tested with an inoculum of 70-80 cfu/well. A pool of normal sera obtained from a number of 4-week old rabbits was used as a source of complement, free of bactericidal antibody activity against group B. After $30 \mathrm{~min}$ at $37^{\circ} \mathrm{C}$, the material was plated onto TSB agar supplemented with $1 \%$ normal horse serum containing $2.5 \%$ vancomycin, colistin and nystatin (Sigma) to inhibit other flora. The bactericidal activity of MAbs 5.8 and 5.9 was compared with negative and positive controls.

Reactivity of the new MAbs with the surface of $N$. meningitidis $B$ by flow cytometry

The ability of C14F10 (5.8) and 7F11B5 (5.9) to bind to the surface of pathogenic strains of $N$. meningitidis B was determined using flow cytometry with detection by indirect immunofluorescence assay. $\mathrm{B}: 4: \mathrm{P} 1.9$ N. meningitidis (whole cells) were washed and resuspended to an optical density of 1.0 at $650 \mathrm{~nm}$ in normal saline (NS) containing 1\% (w/v) bovine serum albumin (Sigma). Bacteria were then mixed in $100 \mu \mathrm{l}$ aliquots with MAb (ascitic fluid) diluted in $200 \mu \mathrm{l}$ of NS/ $\mathrm{BSA}$ and incubated at $37^{\circ} \mathrm{C}$ for $30 \mathrm{~min}$. Normal saline, or "nonsense" IgGMAbs, specific for unrelated proteins $\mathrm{S}$, were employed as negative controls. Antibodyexposed bacteria were washed twice with NS/BSA and mixed with $200 \mu$ l of appropriately diluted FITC-labeled second antibody. The FITC-labeled probe was affinitypurified goat anti-mouse IgG. Bacteria were incubated with FITC-label antibodies for $30 \mathrm{~min}$ at $4^{\circ} \mathrm{C}$, washed twice with NS and resuspended in $1 \mathrm{~mL}$ of NS. As a control, bacteria were incubated in NS-1\% BSA. All 
samples were prepared in triplicate [34]. Positive control MAbs included meningococcal specific serotyping and subtyping. The cells were analyzed by flow cytometry with FACScan (Becton Dickinson, San Jose, CA, US). Each analysis included 5,000 events. One positive histogram gate was defined, allowing a maximum of $2 \%$ of the events of the control experiments to appear in the positive channels. Foward-scatter thresholds and gates were optimized to exclude cell debris and large bacterial aggregates from the analyses. MAb binding was expressed as the percentage of cells fluorescing more intensely than those stained with negative control and unrelated MAb. The monoclonals used in FACS analysis and the IgG-FITC labeled second antibody were used at 1:1000 dilution.

\section{Results}

Specificity of class (5.8) (5.9) MAbs

The specificity of the 2 new MAbs for class 5 epitopes is shown in the Immunoblot study (Figure 1). C14F10 (5.8) and 7F11B5 (5.9). MAb recognized a $28 \mathrm{kD}$ protein in the outer membrane of $N$. meningitidis. To determine whether these MAbs were against known epitopes present in class 5, MAbs C14F10 (5.8) and 7F11B5 (5.9) were used together with existing anti-class 5 Mabs for reaction with a set of meningococcal reference strains. The results confirmed that both MAbs were different from those recognized by existing class 5 specific MAbs (P5.1, P5.3, and P5.4 and P5.5). The epitopes reactive with these MAbs were designated P5.8 and P5.9.

\section{Bactericidal activity and ELISA}

Table 1 shows bactericidal results, using the 2 new MAbs. The reciprocal of the antibody dilution producing $50 \%$ killing of the meningococci was considered to be the bactericidal titer. The 2 new monoclonal antibodies $\mathrm{C} 14 \mathrm{~F} 10 \mathrm{Br} 2$ (5.8) and 7F11B5Br3 (5.9) reacted with OMP and OMC in ELISA, showing the binding of the 2 new MAbs was independent of the procedure used for obtaining the outer membrane antigens (Table 2). The 2 new MAbs, C14F10Br2 (IgG2a) and 7F11B5Br3 (IgG1), showed a strong antibody response to OMP and OMC in ELISA assay and have strong bactericidal activity.

\section{Flow cytometry analysis}

The ability of the C14F10 (5.8) and 7F11B5 (5.9) MAbs to bind to the (5.8) and (5.9) epitopes present on the surface of a pathogenic strain of $N$. meningitidis group B was also determined using FACScan analysis. One example of reactivity of MAbs specific for class 1 , class 3, class 5.8 and 5.9 proteins with whole cells (wc) of a B:4:P1.9 strain can be observed in Figure 2.

\section{Presence of class 5 epitopes}

The whole cell dot blot assay was used to detect the percentage of strains with class 5 proteins expressing (5.1), (5.3), (5.4), (5.5), (5.8), (5.9) and (5.c) epitopes. Table 3 shows the prevalence of class 5 proteins recognized by the monoclonal antibodies on strains isolated in Brazil during epidemics.

Serotype and subtype patterns distribution of $N$. meningiditis in Brazil

The serogroups, serotypes, and subtypes of $N$. meningitidis $\mathrm{B}$ studied were: $\mathrm{B}: 4: \mathrm{P} 1.15, \mathrm{~B}: 4: \mathrm{P} 1.9$, B:4:P1.7, B:4:P1.3, B:4:P1.14, B:4:P1.16, B:4:NT and B:NT:NT. The strains (C:2a:P1.3 ) and (A:4.21:P1.9) were the dominant serotypes and subtypes in $N$. meningitidis $\mathrm{C}$ and $\mathrm{A}$, respectively (Table 4).

\section{Discussion}

Although the class 5 proteins of $N$. meningitidis induce antibodies that are strongly bactericidal against strains expressing the same protein, the occurrence of phase variation reduces the value of these antibodies in protection against group B disease and, thus, the value of their corresponding epitopes as vaccine components. A published paper reported [35] that the composition of the Brazilian meningococcal vaccine will 
probably include a class 5 protein with the P5.5 epitope. However, a great heterogeneity of prevalent N. meningitidis B strains is found in Brazil, which was reflected in the bacterial populations under study as demonstrated in the present investigation.

Comparing the serogroup results obtained with a polyclonal antiserum from the National Reference Center for Meningitis, São Paulo, Brazil, with those obtained with the MAbs directed against serogroupspecific epitopes, discrepancies of only $(2.5 \%)$ for serogroup $\mathrm{A}$, and $3.5 \%$ for serogroup $\mathrm{C}$, and $0 \%$ for serogroup B were observed. This shows the reliability of data on the serogrouping of $N$. meningitidis strains when Brazilian polyclonal antisera are used. These antisera are produced at the Immunology Division of the Adolfo Lutz Institute and distributed to various laboratories in Brazil for use in counterimmunoelectrophoresis and agglutination assays [24].

The vaccine for $N$. meningitidis $\mathrm{B}$, to be prepared in Brazil should contain the (5.5) antigen and (5c), because we found the expression of $5 \mathrm{c}$ to be highly significant. The new MAbs showed that C14F10 (5.8) reacted with $3.6 \%$ of the serogroup $B$ strains investigated, while MAb 7F11B5 (5.9) reacted with $8.8 \%$ of serogroup A, $5 \%$ of serogroup B, and $5 \%$ of serogroup $\mathrm{C}$ strains of $N$. meningitidis isolated during epidemics in Brazil.

Studies on the $5 \mathrm{c}$ protein suggest that future OMV vaccines should be prepared from strains expressing the $5 \mathrm{c}$ protein, but this protein alone will not provide broad protection [22]. On the other hand, this protein is probably not a true class 5 protein [36], although Achtman, et al., considered it a class 5 variant [37]. Whereas class 5 proteins are heat modifiable and antigenically diverse, and their expression is controlled by multiple repeats of the nucleotide sequence CTCTT, the $5 \mathrm{c}$ protein is not heat modifiable, is antigenically conserved, and is not controlled by the CTCTT sequence. The level of 5c expression is variable, a fact that led Achtman, et al. [37], to designate the strains as $5 \mathrm{c}$ and $5 \mathrm{C}$ according to the quantity of protein expressed. The $5 \mathrm{c}$ protein is expressed in about $20 \%$ of serogroup B disease isolates [38].
Our studies using $N$. meningitidis B from the year of 1992, showed that class 5c had a prevalence of $30 \%$ in local Brazilian strains. The $5 \mathrm{c}$ protein is a possible vaccine candidate because it induces bactericidal antibodies. These antibodies may also block tissue invasion. The protein appears to be involved in adherence to, and invasion of, endothelial and epithelial cells. In an in vivo model, it was shown that strains lacking the $5 \mathrm{c}$ protein were largely unable to invade cells, and that antibodies to $5 \mathrm{c}$ could interfere with attachment and penetration [39]. Rosenqvist, et al. [22], found that antibodies to $5 \mathrm{C}$ were strongly bactericidal only for strains expressing large amounts of 5C. Identical results were obtained with 2 human monoclonal antibodies to the $5 \mathrm{C}$ protein [40]. Elevated 5c antibody levels were also seen in convalescent sera, but not in acute sera from meningococcal disease patients. Thus, the protein is antigenically conserved and immunogenic in humans, inducing potentially protective antibodies [22].

Considering the high incidence of meningococcal disease due to certain group B strains in Brazil, the studies of surface structures of class 5 proteins are important. Groups in different Brazilian laboratories have emphasized the importance of class 5 proteins [34, 41, 42] in Brazil. However, no analysis of the prevalence of class 5 types expressed in serogroup B strains in Brazil has been performed, despite the importance of such an analysis for the identification of prevalent class 5 proteins in our strains. The present study shows, for the first time, the importance of Opc (5c) as one of the components of the vaccine to be produced in Brazil. Thus, besides the use of the 5.5 antigen, a broader range of class 5 antigens must be included in a vaccine.

As reported in the literature [43], it is important to establish a broad set of antigens characteristic of the prevalent meningococcal species found in each epidemic region in order to develop truly effective vaccines and immunoprophylactic programs.

\section{Acknowledgements}

We would like to thank JT Poolman of the NIPH for providing some of the MAbs used in this work; Alexandra Carla Fernandes for technical assistance; 
the Cytometry Group of the Lutz Institute for their technical support; and the Bacteriology Section of Adolfo Lutz Institute that isolated the serogroup B strains used in this investigation. This study was funded by Fundação de Amparo à Pesquisa do Estado de São Paulo no 96/5775-3.

\section{References}

1. Peltola H. Meningococcal disease: still with us. Infect Dis 1983;5:71-91.

2. Olyhoek T., Crowe B.A., Achtman M. Clonal population structure of Neisseria meningitidis serogroup A isolated from epidemics and pandemics between 1915 and 1983. Rev Infect Dis 1992;9:665-692.

3. Wang J., Caugant D.A., Morelli G., et al. Antigenic and epidemiological properties of the ET-37 complex of Neisseria meningitis. J Infect Dis 1993;167:1320-9.

4. Achtman M. Global epidemiology of meningococcal disease. In Meningococcal Disease, pp.159-175. Edited by K.Cartwright. Chichester: JohnWiley 1995.

5. Machado M. L'epidemie de meningite cerebro-spinale au Bresil. Med Hyg 1976;34:483-5.

6. Morais J.S., Munford R.S., Risi J.B., et al. Epidemic disease due to serogroup C Neisseria meningitidis in São Paulo Brazil. J Infect Dis 1974;129:568-71.

7. Sacchi C.T., Pessoa L.L., Ramos S.R., et al. On going group B Neisseria meningitidis epidemic in São Paulo, Brazil, due to increased prevalence of a single clone of the ET-5 Complex. J Clin Microbiol 1992;130:1734-8.

8. Hobbs M.M., Marlorny B., Prasad P., et al. Recombinational reassortment among opa genes from ET-37 complex Neisseria meningitidis isolates of diverse geographical origins. Microbiology 1998; $144: 157-66$.

9. Morelli G., Marlorny B., Múller K., et al. Clonal descents and microevolution of Neisseria meningitidis during 30 years of epidemic spread. Mol Microbiol 1997;25:1047-64.

10. Tsai C.M., Frasch C.E., Macca L.F.. Five structural classes of major outer membrane proteins in Neisseria meningitidis. J Bacteriol 1981;146:69-78.

11. Frasch C.E., Zollinger W.D., Poolman J.T. Serotype antigens of Neisseria meningitidis and a proposed scheme for designation of serotypes. Rev Infect. Dis 1985; 7:504-10.

12. Poolman J.T., De Marie S., Zanen H.C. Variability of lowmolecular-weight, heat-modifiable outer membrane proteins of Neisseria meningitidis. Infect Immun 1980;30:642-8.
13. Tensly C.R., Heckels J.E. Variation in the expression of pili and outer membrane proteins by Neisseria meningitidis during the course of meningococcal infection. J Gen Microbiol 1986;132:2483-90.

14. Achtman M., Wall R.A., Bopp M., et al. Variation in class 5 protein expression by serogroup A meningococci during a meningitis epidemic. J Infect Dis 1991; 164:375-82.

15. Woods J.P., Cannon J.G. Variation in expression of class 1 and 5 outer membrane proteins during nasopharyngeal carriage of Neisseria meningitidis. Infect Immun 1990;58:569-72.

16. Aho E.L., Dempxy J.A.,,Hobbs M.M., et al. Characterization of the opa (class5) gene family of Neisseria meningitidis. Mol Microbiol 1991;5:1429-37.

17. Kawula T.H., Aho E.L., Barrit D.S., et al Reversible phase variation of expression of Neisseria meningitidis class 5 outer membrane proteins and their relationship to gonococcal proteins II. Infect Immun 1988;56:38-46.

18. Meyer T.F, van Putten J.P.M. Genetic mechanisms and biological implication of phase variation in pathogenic Neisseriae. Clin Microbiol Rev 1989;2 (suppl.):5:139-45.

19. Bhat K.S., Gibbs C.P., Barrera O., et al. The opacity proteins of Neisseria gonorrhoeae strains MS11 are encoded by a family of 11 complete genes. Mol Microbiol 1991;5:1989-91.

20. Comell T.D., Shaffer D., Cannon J.G. Characterization of the repertoire of hypervariable regions in the protein II (opa) gene family of Neisseria gonorrhoeae. Mol Microbiol 1990;4:439-44.

21. Achtman M., Kuseek B., Morelli G., et al. A comparison of the variable antigens expressed by clone IV-I and subgroup III of Neisseria meningitidis serogroup A. J Infect Dis 1992;165:53-68.

22. Rosenqvist E., Hoiby E.A., Wedge E., et al . The 5C protein of Neisseria meningitidis in highly immunogenic in humans and induces bactericidal antibodies. J Infect Dis 1992; 167:1065-73.

23. Riou J.Y. Diagnostic bactériologique des espéces des genres Neisseria et Branhamella. Ann Biol Clin 1977;35:73-87.

24. Alkmin M.G., Shimizu S.H., Landgraf I.M., et al .Production and immunochemical characterization of Neisseria meningitidis group B antiserum for the diagnosis of purulent meningitis. Brazilian J Med Biol Res 1994;27:1627-34.

25. Kearney J.F, Radbruch A., Liesegang B., et al . A new mouse myeloma cell line that has lost immunoglobulin expression but permits the construction of antibody-secreting hybrid cell lines. J Immunol 1979;132:1548-50. 
26. Kohler G., Milstein C. Continuous cultures of fused cells secreting antibody of predefined specificity. Nature ( London) 1975;256:495-7.

27. Zollinger W.D., Mandrell R.E., Griffiss J.M., et al. A complex of $N$. meningitidis serogroup B polysaccharide and type 2 outer membrane protein immunogenic in man. J Clin Invest 1978;63:836-48.

28. Lowry O.H., Rosebroough J.N., Farr A.L., et al Protein measurement with folin phenol reagent. J Biol Chem 1951;193:265-75.

29. Harthug S., Rosenqvist E., Hoiby E.A., et al. Antibody response in group $\mathrm{B}$ meningococcal disease determined by enzyme-linked Immunosorbent assay with serotype 15 outer membrane antigen. J Clin Microbiol 1986;24:947-53.

30. Rosenqvist E., Wedege E., Hiby A., et al. Serogroups determination of Neisseria meningitidis by whole-cellELISA, dot-blotting and agglutination. APMIS 1990;98:501-6.

31. Laemmli U.K. Cleavage of structural proteins during assembly of the head of bacteriophage T4. Nature (London) 1970;227:680-5.

32. Towbin H., Staehelin T., Gordon J. Electroforetic transfer of proteins from polyacrylamide gels to nitrocellulose sheets: procedure and some implicatins. Proc Natl Acad Sci USA 1979;76:4350-4.

33. Hfiby E.A., Rosenqvist E, Foholm L.O, et al . Bactericidal antibodies after vaccination with the Norwegian meningococcal serogroup B outer membrane vesicle vaccine: a brief survey. NIPH Ann 1991; 14:147-56.

34. De Oliveira L.M.C., De Gaspari E.N. Study of the new cross a reactive monoclonal antibody against Neisseria meningitidis using flow cytometry Analysis. Analyt Celular Pathol 1997; 14:191.

35. Sacchi C..T., Gorla M..C.O, De Lemos A..P.S, et al . Considerations on the use of Neisseria meningitidis class 5 proteins as meningococcal $\mathrm{BC}$ vaccine components. Vaccine 1986; 13 : 112-8.

36. Achtman M., Kusecek B., Morelli., et al. A comparison of the variable antigens expressed by clone IV-1 and subserogroup III of Neisseria meningitidis serogroup A. J Infect Dis 1992;165:53-68.

37. Achtman M., Neibert M., Crowe B.A., et al. Purification and caracterization of eight class 5 outer membrane protein variants from a clone of Neisseria meningitidis serogroup A. J Exp Med 1988; 168:507-26.

38. Frasch C.E. Meningococcal Vaccines: Past, Present and Future. In: Keith Cartwright eds. Meningococcal Disease. John Wiley \& Sons Ltda eds, Baffins Lane, Chichester, England 1995:245-83.

39. Virji M., Nakepeace K., Ferguson D.J.P., et al. Expression of the Opc protein correlates with invasion of epithelial and endothelial cells by Neisseria meningitidis. Mol Microbiol 1992;6:2785-95.
40. Fernandez de Cossio M.E., Ohlin M., Selender B., et al. Human monoclonal antibody against one epitope on the class $5 \mathrm{c}$ outer membrane protein common to many pathogenic strains of Neisseria meningitidis. J Infect Dis 1992; 166:1322-8.

41. Danelli M.D.G., Batoreu N.M., Lacerda M.D., et al. Surface antigens analysis of group B Neisseria meningitidis Outer membrane by monoclonal Antibodies: Identification of bactericidal antibodies to class 5 protein. Current Microbiology 1995; 31:146-151.

42. Danelli M.D.G., Alves C.M.A, Bastos R.C., et al. Human immune response to epitopes on the meningococcal outer membrane class 5 protein following natural infection FEMS Immunol and Medical Microbiology 1996; 15:159-68.

43. Zollinger W.D., Moran E. Meningococcal vaccines present and futher. Trans Roy Soc Trop Med Hyg 1991;85(suppl):37- 43 . 


\section{Pneumocystis carinii Pneumonia, Pulmonary Tuberculosis and Visceral Leishmaniasis in an Adult HIV Negative Patient}

Antonio Carlos Toledo Jr. and Márcio Rodrigues de Castro
Eduardo Menezes Hospital, Hospitalar

Foundation of Minas Gerais, MG, Brazil

This is a case report of a 29 year old male with pneumocystis pneumonia and tuberculosis, and who was initially suspected of having HIV infection, based on risk factor analyses, but was subsequently shown to be HIV negative. The patient arrived at the hospital with fever, cough, weight loss, loss of appetite, pallor, and arthralgia. In addition, he was jaundiced and had cervical lymphadenopathy and mild heptosplenomegaly. He had interstitial infiltrates of the lung, sputum smears positive for Mycobacterium tuberculosis and Pneumocystis carinii, and stool tests were positive for Strongyloides stercoralis and Schistosoma mansoni. He was diagnosed as having AIDS, and was treated for tuberculosis, pneumocystosis, and strongyloidiasis with a good response. The patient did not receive anti-retroviral therapy, pending outcome of the HIV tests. A month later, he was re-examined and found to have worsening hepatosplenomegaly, pancytopenia, fever, and continued weight loss. At this time, it was determined that his HIV ELISA antibody tests were negative. A bone marrow aspirate was done and revealed amastigotes of leishmania, and a bone marrow culture was positive for Leishmania species. He was treated with pentavalent antimony, $20 \mathrm{mg}$ daily for 20 days, with complete remission of symptoms and weight gain. This case demonstrates that immunosuppression from leishmaniasis and tuberculosis may lead to pneumocystosis, and be misdiagnosed as HIV infection. The occurrence of opportunistic infections in severely ill patients without HIV must always be considered and alternate causes of immunosuppression sought.

Key Words: Pneumocystis carinii, visceral leishmaniasis, tuberculosis, HIV diagnosis, opportunistic infections.

We describe a case of $P$. carinii pneumonia as a complication of visceral leishmaniasis in an HIV negative patient. Visceral leishmaniasis (VL) is a chronic infectious disease characterized by an important immunological dysfunction that predisposes to other infections, mainly involving the pulmonary and gastrointestinal systems. In Brazil, bacterial pneumonia and tuberculosis are frequent opportunistic infections in this disease. $P$. carinii is a ubiquitous organism that

Received on 31 March 2001; revised 27 May 2001.

Address for correspondence: Dr. Antonio Carlos Toledo Jr. Rua Mário Coutinho, 541/304, Zip code: 30570-310 - Belo Horizonte-MG-Brazil. Phone (55 31) 3290-2968. Fax (55 31) 3290-2977.

The Brazilian Journal of Infectious Diseases 2001;5(3):154-157 (C) 2001 by The Brazilian Journal of Infectious Diseases and Contexto Publishing. All rights reserved.

$1413-8670$ commonly causes disease in immunodeficient patients such as in cancer, HIV/AIDS, leukemia, lymphoma, and transplant recipients [1]. Although there is no description of $P$. carinii pneumonia as an opportunistic infection of VL in the medical literature, it is plausible that immunodysfunction induced by Leishmania could be responsible for this patient's illness. If so, this would be the first description of an association of VLand $P$. carinii pneumonia.

\section{Case report}

A 29 year old male patient, was admitted to Hospital Eduardo de Menezes (Infectious Diseases Hospital of Minas Gerais State, Brazil) on October 16, 1995. He complained of fever, asthenia, weight loss (>10 kg), loss of appetite, generalized arthralgia and a productive cough. Past history indicated 2 blood transfusions and 